
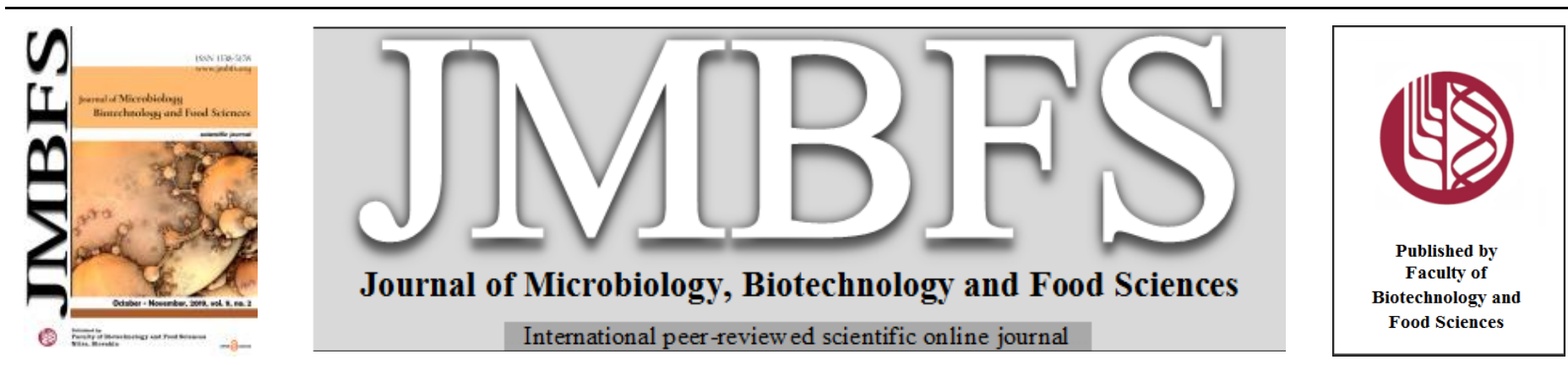

\title{
INSTANT RICE PROCESS DEVELOPMENT: EFFECT OF RICE COOKING METHODS ON THE QUALITY OF JASMINE INSTANT RICE DRIED BY INDUSTRIAL MICROWAVE OVEN
}

\author{
Patsakul Phukasmas ${ }^{l}$, Sirichai Songsermpong*l \\ Address(es): Dr. Sirichai Songsermpong, \\ ${ }^{1}$ Department of Food Science and Technology, Faculty of Agro-Industry, Kasetsart university, Bangkok 10900, Thailand.
}

*Corresponding author: sirichai.so@ku.ac.th

doi: 10.15414/jmbfs.2019.9.2.330-334

\section{ARTICLE INFO}

Received 14. 10. 2018

Revised 20. 6. 2019

Accepted 20. 6. 2019

Published 1. 10. 2019

Regular article open $\partial_{\text {access }}$

\begin{abstract}
Rice is considered as a staple food, which approximately half of the world population consumes. However, it is apparent that rice surplus and low price problem still remain. Consequently, instant rice has been promoted in order to tackle with the present issue and open more choices to the consumers. The current problem of commercial instant rice is slow rehydration and poor quality. This research focused on the rice cooking methods to improve the quality of instant rice dried by industrial microwave oven. Four cooking methods were investigated: Boiling in a pressure cooker (BPC), Steaming in a pressure cooker (SPC), Boiling water method (BL) and Steaming method (SM). The industrial microwave oven $(6,400$ watt, $2,450 \mathrm{MHz})$ was used to dry the cooked rice in each treatment to the moisture content lower than $14 \%$ (w.b.). The results showed that the hardness, stickiness and whiteness of rehydrated rice cooking by different methods had no significant difference with freshly cooked rice. BPC method is the recommended method for instant rice processing since it could provide more porous structures after drying, which relate to fast rehydration for 3 minutes in boiling water and better quality. Furthermore, after rehydration process, the grain appearance was pretty good and did not stick together. Therefore, this knowledge can be applied for the instant rice production at the industrial level.
\end{abstract}

Keywords: Cooking methods, Industrial microwave oven, Instant rice, Quality

\section{INTRODUCTION}

Rice is considered as a major agricultural product of Thailand, and it is the main Thai staple food. In 2017, Thailand exports the highest amount to the world rice market (USDA, 2017). In the present day, the lifestyle has changed, Thai people have a hustle life, more convince and less attention for food preparation (Srichamnong et al., 2016). Jasmine rice (KDML 105 variety) is the most popular aromatic rice variety grown in Thailand because of its famous reputation in appearance, cooking quality and high aroma level. Jasmine rice is well known rice cultivar, since unique aroma from 2-acetyl-1-pyrroline, which exhibit popcorn-like aroma (Ranalli et al., 2003). Furthermore, cooked jasmine rice has specific characteristic with the soft and sticky texture (Phanchaisri et al., 2007). Instant rice could be an answer for this lifestyle situation, including for travelers, and natural disaster victims (Prasert and Suwannaporn, 2009). There are many different ways to cook rice and have an effect with the quality of instant rice (Kassem et al., 2011; Sripinyowanich and Noomhorm, 2011; Wang et al., 2013). Drying of instant rice plays a pivotal role in the quality of the product. Most researches used hot air drying and faced the problem of long dehydration time and slow rehydration rate (Tein et al, 1998; Zhao et al., 2007; Sripinyowanich and Noomhorm, 2011). Therefore, the quality of instant rice doesn't meet the needs of consumers. However, commercial instant rice is still faced with many problems such as long rehydration time, poor quality and physical appearance including rice agglomeration. There are many researches which solve the instant rice production but still cannot rehydrate within 3 minutes with good quality (Narkrugsa and Thunyawanith, 2002; Rewthong et al., 2011; Chen et al., 2014; Huang et al., 2014). A very interesting method is microwave drying (Seremet et al., 2016). Jaroenkit et al. (2013) produced instant rice by using home microwave oven that could produce instant rice with good quality and did not change the nutritional value. It was found that drying by microwave resulted in the better quality of instant rice products. Moreover, the water uptake ratio increased and the rehydration time decreased as the drying temperature increased (Sripinyowanich and Noomhorm, 2012) and hightemperature drying resulted in large porous structure within the rice grain, which helped to rehydrate grain (Prasert and Suwannaporn, 2009).

The objective of this work was to investigate the effect of rice cooking methods on the quality of instant rice dried by industrial microwave oven. Drying curve, whiteness, volume expansion, microstructure, texture and rehydration time of instant rice were investigated. In order to produce fast rehydration instant rice, loosed grain and good physical appearance. The microwave drying method was used to dehydrate instant rice. Therefore, it is hoped that this research can help to solve the problem of surplus and low price and prolong the shelf life, and can increase the export value of rice to foreign countries as well.

\section{MATERIAL AND METHODS}

\section{Preparation of instant rice}

Jasmine rice (Khao Dok Mali 105) was obtained from the Office of Agricultural Cooperatives, Roiet, with the moisture content of $12.73 \pm 0.07 \%$ dry basis (d.b.). The rice sample was kept in storage room at $0^{\circ} \mathrm{C}$ until use.

\section{Cooking methods for instant rice}

Jasmine rice was brought to room temperature and cooked by a pressure cooker (Siam Medical Import Co., Ltd., Thailand) and cooked by stainless steel pot (Satien Stainless Steel Public Co., Ltd., Thailand) for conventional methods, using 500 grams of rice per condition. (McCabe, 1976; Narkrugsa and Thunyawanith, 2002; Prasert and Suwannaporn, 2009). Four cooking method were investigated; Boiling in a pressure cooker (BPC), Steaming in a pressure cooker (SPC), Boiling in a stainless steel pot (BL), and Steaming in a stainless steel pot (SM).

For Boiling in a pressure cooker (BPC) and boiling in a stainless steel pot (BL). The rice to water ratio was $1: 5(\mathrm{w} / \mathrm{w})$. The temperature was set at $105^{\circ} \mathrm{C}$ and held for 10 minutes in pressure and conventional rice cooker for BPC and BL condition respectively. BPC and SPC in pressure cooker had the temperature controller. BL and SM could be controlled cooking temperature of each method were determined using a programmable temperature data logger and commercial electric hot plate. Then cooked rice was submerged in cold water $\left(0^{\circ} \mathrm{C}\right)$ for 1 minutes and drain prior to drying process.

For steaming rice in a pressure cooker (SPC) and steaming in a stainless steel pot $(\mathrm{SM})$, the rice was immersed in water at room temperature until rice has the moisture content of $30 \%$ dry basis with $1: 3(\mathrm{w} / \mathrm{w})$ ratio of rice to water for 1 
hour. After that, soaked rice was put into cheesecloth and $150 \mathrm{ml}$ of water was sprayed. Prior to cook with pressure and conventional steam rice cooker for SPC and $\mathrm{SM}$ respectively, at $105^{\circ} \mathrm{C}$ for 30 minutes until completely cooked (fully gelatinized). After that, cooked rice was soaked in cold water $\left(0^{\circ} \mathrm{C}\right)$ for 1 minutes and drain out. To separate rice grain from the water, after rice cooking, the sample from four conditions was submerged into liquid nitrogen $\left(-196 \pm 0.24^{\circ} \mathrm{C}\right)$ to prevent agglomeration of rice before drying and dried by microwave drying immediately. The processing experiment plan is shown at flowchart (Fig 1).

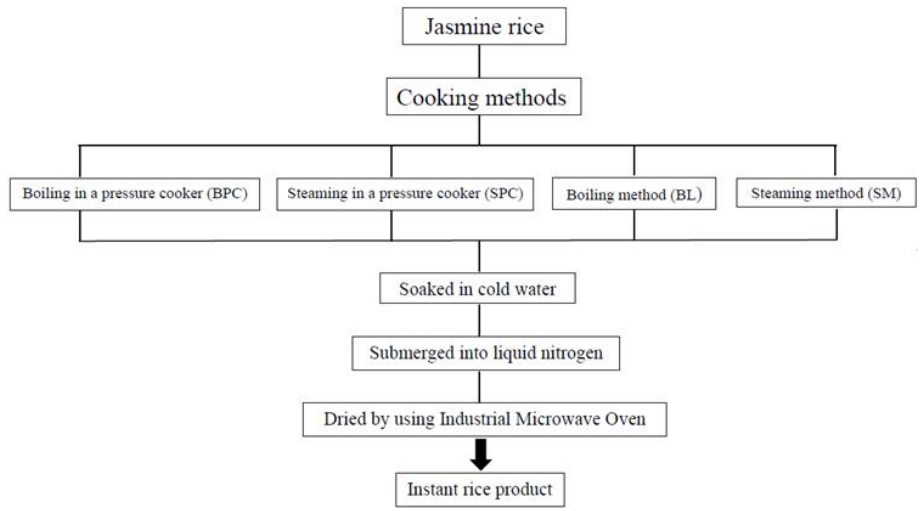

Figure 1 Flowchart and experimental plan for preparing instant rice

\section{Microwave drying treatment}
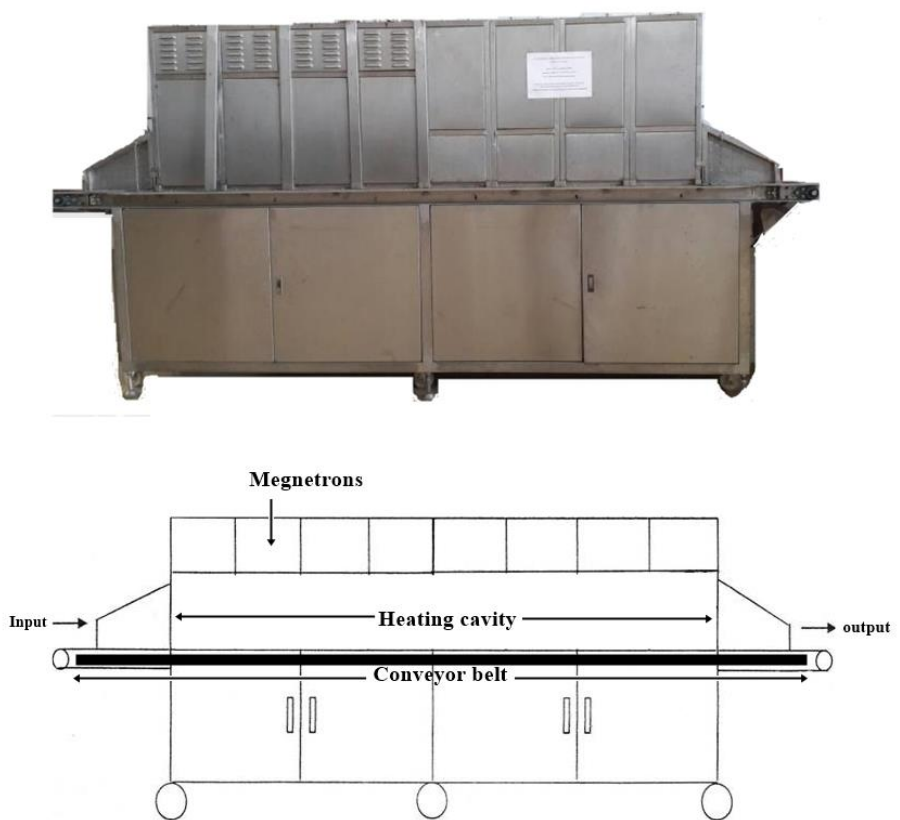

Microwave drying was done by using industrial microwave oven (continuous microwave oven) developed by PrimAsia Technology (Thailand). Schematic diagram was shown in figure 2 . This machine consisted of eight magnetrons $(6,400$ watt), the frequency of $2,450 \mathrm{MHz}$. The cavity of microwave was made of stainless steel with outer dimension at $800 \mathrm{~mm}$ x 4,000 $\mathrm{mm} \times 1,700 \mathrm{~mm}$ (Width $\mathrm{x}$ Length $\mathrm{x}$ Depth). The frozen rice was transferred to the teflon conveyor belt, which set the speed at 40 Hertz $(0.7 \mathrm{~m} / \mathrm{min})$ to transfer sample $(120$ grams per min) into microwave cavity for drying process. Drying was continued until the final moisture content was lower than $14 \%$ wet basis (TACFS, 2017).

Figure 2 Schematic illustration of industrial microwave oven (PrimAsia Technology, Thailand)

\section{Determination of qualities of instant rice}

\section{Moisture content determination during microwave drying}

The moisture content of instant rice was determined in triplicate following AOAC (2000) method. The moisture content of sample was determined by hot air oven. 10 grams of sample from each condition was dried at $105^{\circ} \mathrm{C}$ for 24 hour, and weight difference was measured and calculated in percent wet basis. The moisture content of sample was calculated from following equation.

$\mathrm{M}_{\mathrm{W}}=\frac{\mathrm{W}-\mathrm{W}_{\mathrm{D}}}{\mathrm{W}} \times 100$
Where Mw is moisture content of rice on wet basis, $\mathrm{w}$ is the weight of rice (in grams), $w_{D}$ is the dry matter weight of rice (in grams).

\section{Rehydration ratio and rehydration time}

The instant rice was filled with boiling water $\left(100^{\circ} \mathrm{C}\right)$ to rehydrate by using rice to water ratio as $1: 1.25(\mathrm{w} / \mathrm{w})$ in polypropylene $(\mathrm{PP})$ plastic cup. The rehydration time was recorded when the rehydrated instant rice is soft and more than 90 grains of 100 grains were absent of hard core inside (Sripinyowanich and Noomhorm, 2012). Three replications were carried out. The Rehydration ratio was calculated according to Prasert and Suwannaporn (2009). The water rehydration ratio was calculated from equation below.

Rehydration ratio $(\mathrm{RR})=\frac{\text { weight of rice rehydrated }(\mathrm{g})-\text { weight of rice before rehydration }(\mathrm{g})}{\text { weight of rice before rehydration }(\mathrm{g})}$

\section{Microstructure evaluation}

The structure of the instant rice after drying was investigated by using a scanning electron microscope (Hitachi TM3030 plus, Hitachi, Krefeld, Germany) with $500 \times$ magnification for the surface and cross section. The morphological changes of the appearance and pore size were characterized using an acceleration voltage of $15 \mathrm{kV}$ electron intensity.

\section{Texture characteristics}

The hardness of rehydrated instant rice was measured by the Texture analyzer (TA-XT plus, Stable Micro System, England) with $35 \mathrm{~mm}$ spherical plate. 15 grams of cooked instant rice was pressed and compression distance was $50 \%$ strain of the height and pre-test speed, test speed and post-test speed of the plunger were set at 1.0, 1.0 and $10 \mathrm{~mm} / \mathrm{s}$, respectively (Leelayuthsoontorn and Thipayarat, 2006). 10 replications were performed. The maximum forces were averaged and reported as hardness. The maximum negative forces were reported as stickiness.

\section{Whiteness index (WI) measurement}

Instant rice of 100 grams was sampled and the color was measured by using a HunterLab MiniScan XE plus colorimeter (Hunter Associates Laboratory Inc, USA). The color parameters were measured in CIELAB color system. L* is a measure of the lightness, $\mathrm{a}^{*}$ describes as redness-greenness and $\mathrm{b}^{*}$ describes as yellowness-blueness. Thereafter, the whiteness index of instant rice was calculated by using the following equation (Leelayuthsoontorn and Thipayarat, 2006).

$\mathrm{WI}=100-\left[(100-\mathrm{L})^{2}+\mathrm{a}^{2}+\mathrm{b}^{2}\right]^{0.5}$

\section{Volume expansion}

The volume expansion of the product was performed by measuring the volume of the $100 \mathrm{~g}$ instant rice by using graduated cylinder. Then measure the volume of the instant rice again after rehydration as shown in the equation (Prasert and Suwannaporn, 2009)

Volume

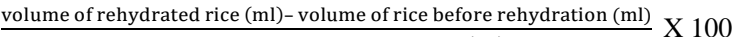
expansion $=$

\section{Statistical analysis}

Analysis of variance (ANOVA) was performed by using a statistical SPSS software (Version 17; SPSS Inc.; Chicago, IL, USA). Comparison between means were examined using Duncan multiple range test (DMRT) at $p \leq 0.05$ significance level. The results from three replications were presented as means values with standard deviations.

\section{RESULTS AND DISCUSSION}

\section{Drying Characteristics}

The drying curves of the instant rice by microwave drying from different rice cooking methods are shown in figure 3. There are two stages of drying: moisture content is reduced rapidly and slowly when the drying is near completion. The first period is within 10 minutes of drying process; the moisture content is dramatically decreased. However after 10 minutes of drying, the moisture content slowly decreases when the moisture content is close to the completion state. At first, instant rice had a moisture content range of 64.79 to 70.83 (\%d.b.). During first period of drying, the moisture content decreases in a linear manner, which is called a constant drying rate. Then the moisture content reduced slowly which called a falling rate (Feng $\boldsymbol{e t}$ al., 2012). According to Thai rice standard (TACFS, 2017), instant rice should have a moisture content less than $14 \% \mathrm{wb}$. or 
$16 \% \mathrm{db}$. to prevent microbial spoilage. In addition, both SPC and BPC showed more reduction in moisture and faster dehydration rate. Specifically, in SPC and BPC method took 35 minutes and 40 minutes respectively. However, in SM and BL method, which used conventional rice cooker instead of pressure cooker. It took longer time in dehydration, 50 minutes and 60 minutes for SM and BL respectively. Effect of the cooking methods on the drying of the instant rice was significant $(\mathrm{p} \leq 0.05)$. For the reason that, pressure cooker increased the pressure inside the rice grain and created porous structures when coupling with microwave caused the volumetric heating. It can generate heat inside of the product. As consequence, the moisture inside grain became steam and moved rapidly to the surface. This phenomenon will generate big and more porous structures. On the other hand, BL method, the grain had higher moisture content and drying rate was slower than other cooking methods.

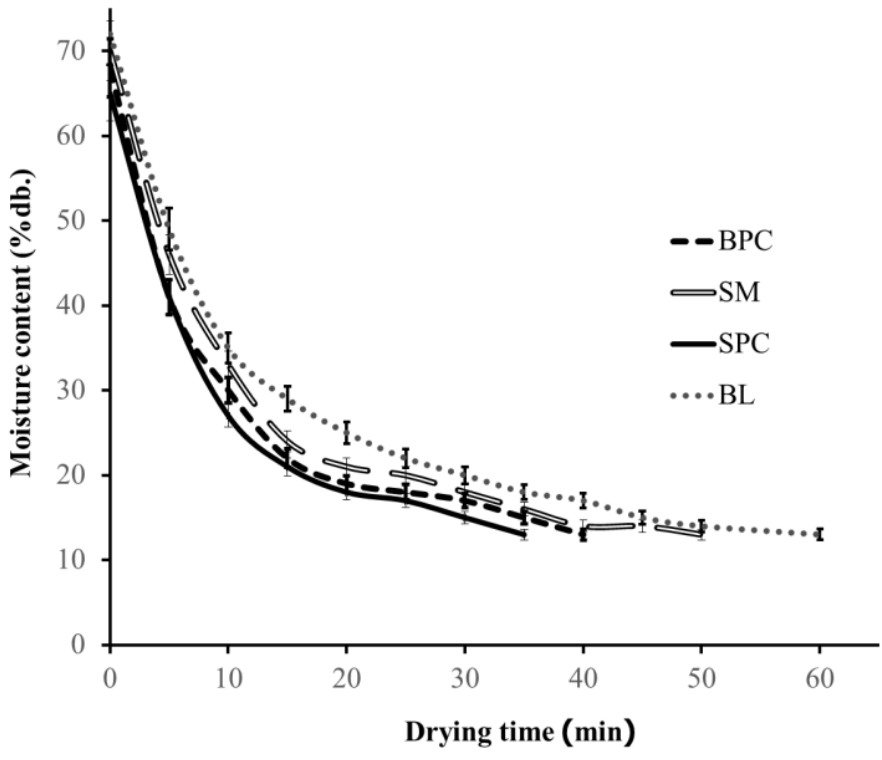

Figure 3 Drying curve of instant rice from different cooking methods drying with industrial microwave oven (error bars $= \pm \mathrm{SD}$ )

\section{Rehydration ratio and rehydration time}

The rehydration curves of instant rice are presented in figure 4 and appearance of instant rice are presented in figure 5. It was shown that the rehydration ratio was increased with increase in the rehydration time. BPC method showed the fastest rehydration time ( 3 minutes) and after rehydration process the grain appearance was similar to freshly cooked rice and it was individually separated. On the other hand, SPC, BL and SM showed slower in rehydration time about 4.5 minutes, 5.5 minutes and 7 minutes respectively. BPC (Fig 5A) can rehydrate faster since the rice grains structure has plenty of pores which increase accessibility of hot water to penetrate inside of rice faster than other rice cooking conditions.

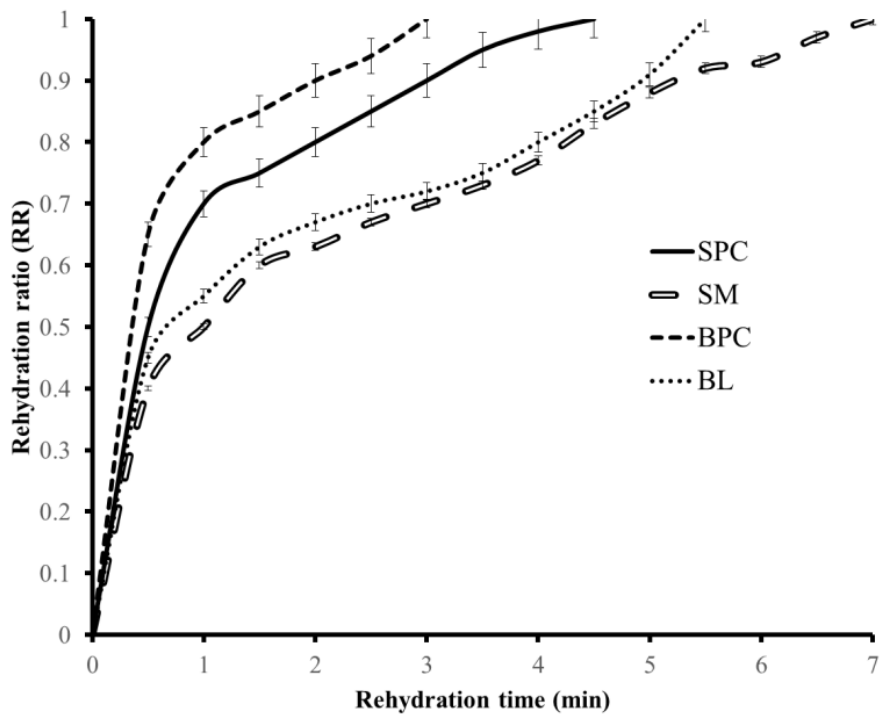

Figure 4 Rehydration ratio of instant rice from different cooking methods (error bars $= \pm \mathrm{SD}$ )

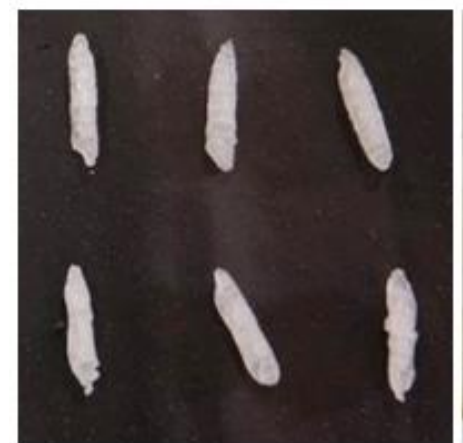

(A)
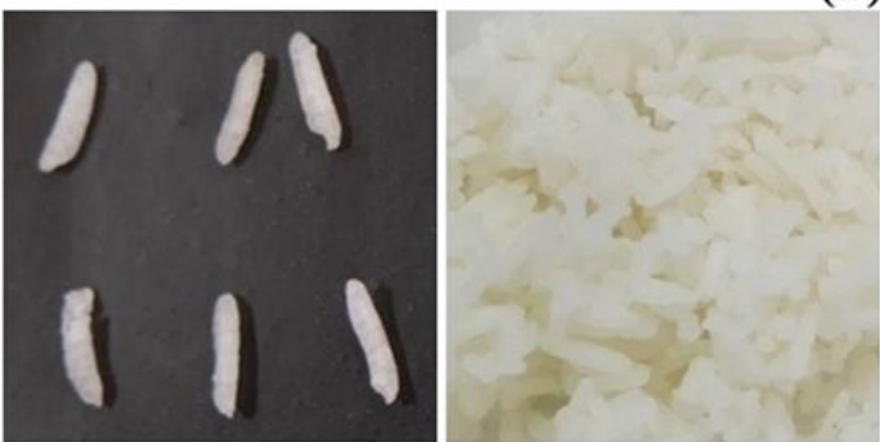

(B)
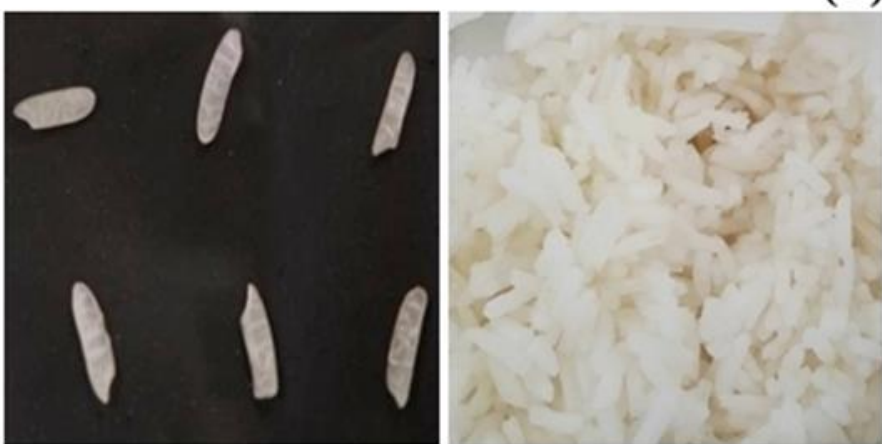

(D)
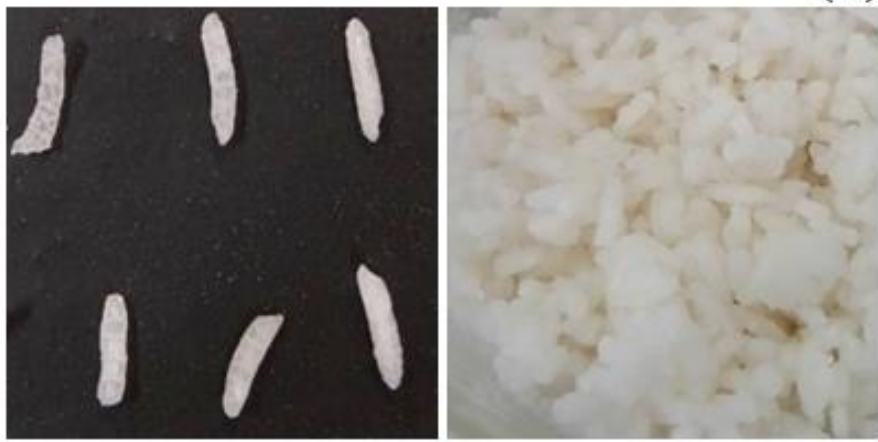

Figure 5 Appearance of instant rice (dried sample) and instant rice (rehydrated sample) from different cooking methods: (A) BPC (B) SPC (C) SM (D) BL

\section{Microstructure evaluation}

The instant rice by BPC method showed the more porous structures on the surface than SPC in the pressure cooker condition. This porous structure made the rehydration faster. Instant rice from BPC condition was expressed in figures $6 \mathrm{~A}$ and $6 \mathrm{E}$. It was apparent that there are plenty of pores at the surface, big cracks in the cross section and more spongy structure. The SM and BL methods sample (Figs 6C and 6D) showed small pores on the surface and small cracks in the cross section (Figs 6G and 6H), comparing with BPC and SPC methods. From the research of Prasert and Suwannaporn (2009) and Sripinyowanich and Noomhorm (2012), they found that using pressure cooker can increase pores in the grain structure. As consequences, it can increase the surface area for contact with water and absorb water quickly. Furthermore, BPC had bigger pore sizes and more porous structure due to more water during cooking in the pressure cooker. 
Surface

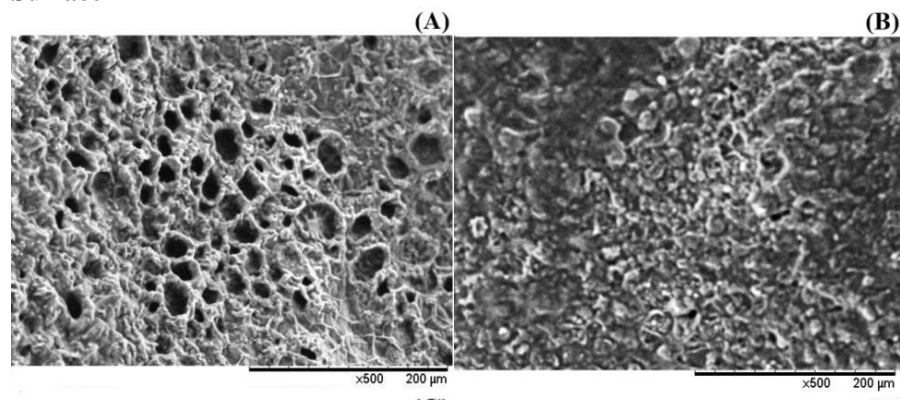

(C)
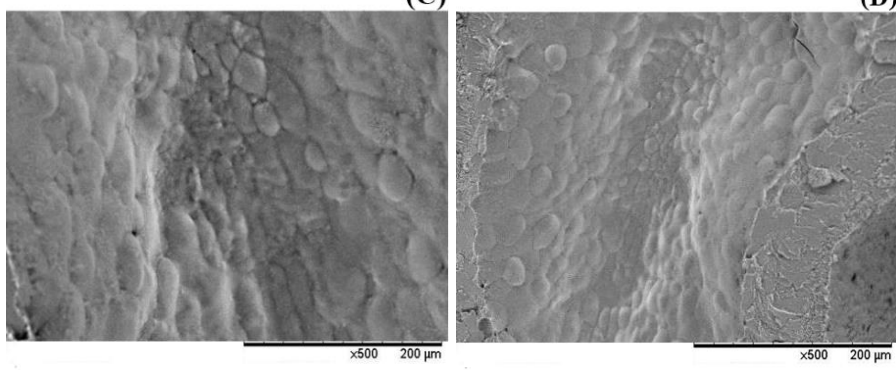

Cross section

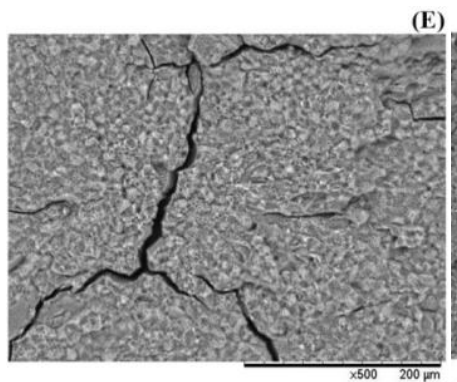

(E)

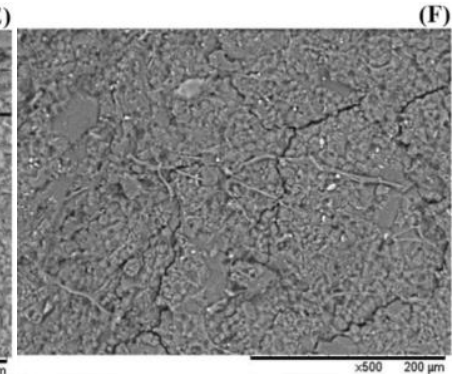

(H)

(G)

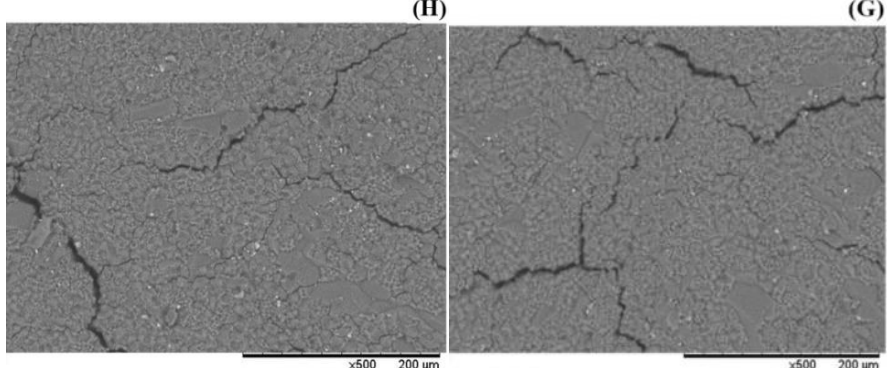

Figure 6 Scanning electron micrographs of surface and cross section of instant rice (dried sample) from different cooking methods: $(\mathrm{A}, \mathrm{E}) \mathrm{BPC}(\mathrm{B}, \mathrm{F}) \mathrm{SPC}(\mathrm{C}, \mathrm{G})$ SM (D,H) BL

\section{Hardness, stickiness, whiteness and volume expansion of instant rice}

The hardness of dried instant rice obtained from SM was higher than other cooking methods. In Table 1 shows the hardness and stickiness of dried instant rice after rehydration process. It was found that the hardness of rehydrated instant rice was in the range of 32.71-33.87 N. In contrast, cooking with the pressure cooker (SPC and BPC), boiling (BL) and steaming (SM) did not significantly affect to the hardness and stickiness of rehydrated instant rice. The hardness and stickiness of rehydrated instant rice corresponded to the volume expansion which was not significantly different after rehydration. The whiteness of rehydrated instant rice from different cooking methods have shown no significant difference with the freshly cooked rice. Simultaneously, there was no significant difference in term of hardness and whiteness of rehydrated instant rice, which means the cooking method did not affect physical properties of rehydrated instant rice. The volume expansion of BPC after rehydration in boiling water for 3 minutes is presented in Table 1. These results revealed that cooking method did not affect the volume expansion of rehydrated instant rice which is similar to the results of Prasert and Suwannaporn (2009). From Table 1, it was found that the volume expansion of instant rice, which dried by industrial microwave oven is lower and this showed the similar result with Jiao et al., (2014), who found the rapid drying method provide lower volume expansion. Since the heat from drying process was used to evaporate water, which can generate porous structure within the grain resulting in lower volume expansion.

Table 1 Hardness, stickiness, whiteness and volume expansion of instant rice from different cooking methods

\begin{tabular}{lcccc}
\hline Cooking methods & Hardness $(\mathbf{N})$ & Stickiness $(\mathbf{N})$ & Volume expansion $(\%)$ & Whiteness index (WI) \\
\hline Freshly cooked rice & $33.87 \pm 0.75^{n s}$ & $18.24 \pm 2.18^{\mathrm{ns}}$ & $66.73 \pm 1.35^{\mathrm{ns}}$ & $76.38 \pm 1.32^{\mathrm{ns}}$ \\
SPC & $33.42 \pm 0.08^{\mathrm{ns}}$ & $18.63 \pm 1.35^{\mathrm{ns}}$ & $66.58 \pm 1.47^{\mathrm{ns}}$ & $76.20 \pm 0.11^{\mathrm{ns}}$ \\
BPC & $33.96 \pm 1.24^{\mathrm{ns}}$ & $17.98 \pm 0.52^{\mathrm{ns}}$ & $66.45 \pm 0.85^{\mathrm{ns}}$ & $76.31 \pm 0.02^{\mathrm{ns}}$ \\
BL & $32.92 \pm 1.03^{\mathrm{ns}}$ & $17.93 \pm 0.36^{\mathrm{ns}}$ & $65.23 \pm 0.04^{\mathrm{ns}}$ & $75.56 \pm 3.42^{\mathrm{ns}}$ \\
SM & $32.71 \pm 0.04^{\mathrm{ns}}$ & $17.87 \pm 3.64^{\mathrm{ns}}$ & $65.39 \pm 0.92^{\mathrm{ns}}$ & $75.11 \pm 0.78^{\mathrm{ns}}$ \\
\hline
\end{tabular}

\section{CONCLUSION}

In conclusion, the results from this experiment showed that the cooking methods has an influence on the quality of dried instant rice. The cooked rice that dried with industrial microwave oven $(6,400$ watt, $2,450 \mathrm{MHz})$ until the final moisture content was lower than ( $14 \%$ w.b.) to prevent microbial degradation. The use of industrial microwave oven represents a great alternative drying method since the rice grain was not broken, did not stick together and had better physical appearance. It can be concluded that cooking methods with the pressure cooker (SPC and BPC), boiling (BL) and steaming (SM) had no significantly difference on the hardness, stickiness and whiteness with freshly cooked rice. For more specific, BPC was the great cooking method to produced instant rice, since it could provide the least rehydration time within 3 minutes and more porous surface of instant dried rice. Therefore, BPC method combined with industrial microwave oven was recommended to produce better quality of instant rice with fast rehydration and good quality.

Acknowledgments: This research was financially supported by the Graduate Program Scholarship from The Graduate School, Kasetsart University, Bangkhen campus, Bangkok, Thailand.

\section{REFERENCES}

AOAC "Association of Official Analytical Chemists" (2000).Official Methods of Analysis. Association of Official Analytical Chemists. $17^{\text {th }}$ Ed., Washington, DC, USA.
Chen, X., Qian, P., Zhang, X., Liu, F., Lu, R. (2014). Improving instant rice quality by novel combined drying. Drying Technology, 32, 1448-1456 http://dx.doi.org/10.1080/07373937.2014.900503

Feng, H., Yin, Y., Tang, J. (2012). Microwave drying of food and agricultura materials: basics and heat and mass transfer modeling. Food Engineering Reviews, 4, 89-106. http://dx.doi:10.1007/s12393-012-9048-x

Huang, M., He, G., Chen S., Cui, M., Ma, L., Liu, Y. (2014). Optimisation of a quality improver for instant rice and its quality properties. International Journal of Food Science and Technology, 49, 606-615. https://doi.org/10.1111/ijfs.12343 Jaroenkit, P., Matan, N., Nisoa, M. (2013). Microwave drying of cooked brown rice and the effect on the nutrient composition and trace elements. International Food Research Journal, 20, 351-355.

Jiao, A., Xu, X., Jin, Z. (2014). Modelling of dehydration rehydration of instant rice in combined microwave-hot air drying. Food and Bioproducts Processing, 92, 259-265. https://doi.org/10.1016/i.fbp.2013.08.002

Kassem, A.S., Shokr, A.Z., El-Mahdy, A.R., Aboukarima, A.M., Hamed, E.Y. (2011). Comparison of drying characteristics of Thompson seedless grapes using combined microwave oven and hot air drying. Journal of the Saudi Society of Agricultural Sciences, 10, 33-40. https://doi.org/10.1016/j.jssas.2010.05.001 Leelayuthsoontorn, P., Thipayarat, A. (2006). Textural and morphological changes of Jasmine rice under various elevated cooking conditions. Food Chemistry, 96, 606-613. https://doi.org/10.1016/j.foodchem.2005.03.016

McCabe, D. (1976). Process for preparing a quick-cooking brown rice and the resulting product, US patent $3,959,515$

Narkrugsa, W., Thunyawanith, S. (2002). The quality improvement of quick cooking rice by freezing and microwave technique. Journal of the National Research Council of Thailand, 37, 125-142. 
Phanchaisri, B., Chandet, R., Yu, L.D., Vilaithong, T., Jamjod, S., Anuntalabhochai, S. (2007). Low-energy ion beam-induced mutation in

Thai jasmine rice (Oryza sativa L. cv. KDML 105). Surface and Coatings Technology, 201, 8024-8028. https://doi.org/10.1016/j.surfcoat.2006.02.057

Prasert, W., Suwannaporn, P. (2009). Optimization of instant jasmine rice process and its physicochemical properties. Journal of Food Engineering, 95, 5461. https://doi.org/10.1016/j.jfoodeng.2009.04.008

Ranalli, R.P., Howell T.A., Siebenmorgen, T.J. (2003). Effects of controlled ambient aeration on rice quality during on-farm storage. Cereal Chemistry, 80, 912. https://doi.org/10.1094/CCHEM.2003.80.1.9

Rewthong, O., Soponronnarit, S., Taechapairoj, C., Tungtrakul, P., Prachayawarakorn, S. (2011). Effects of cooking, drying, and pretreatment methods on texture and starch digestibility of instant rice. Journal of Food Engineering, 103, 258-264. https://doi.org/10.1016/j.jfoodeng.2010.10.022

Seremet, L., Botez, E., Nistor, O., Andronoiu, D.G., Mocanu, G. (2016). Effect of different drying methods on moisture ratio and rehydration of pumpkin slices. Food Chemistry, 195, 104-109. https://doi.org/10.1016/j.foodchem.2015.03.125

Srichamnong, W., Thiyajai, P., Charoenkiatkul, S. (2016). Conventional steaming retains tocols and $\gamma$-oryzanol better than boiling and frying in the jasmine rice variety Khao dok mali 105. Food Chemistry, 191, 113-119. https://doi.org/10.1016/j.foodchem.2015.05.027

Sripinyowanich, J., Noomhorm, A. (2011). A new model and quality of unfrozen and frozen cooked rice dried in a microwave vibro-fluidized bed dryer. Drying Technology, 29, 735-748. https://doi.org/10.1080/07373937.2010.535399

Sripinyowanich, J., Noomhorm, A. (2012). Effects of freezing pretreatment microwave assisted vibro-Fluidized bed drying and drying temperature on instant rice production and quality. Journal of Food Processing and Preservation, 37, 314-324. https://doi.org/10.1111/j.1745-4549.2011.00651.x

TACFS. 2017, Thai hom mali rice. Thai agricultural commodity and food standard. (2017). Retrieved Feburary 10, 2018, from http://www.acfs.go.th/standard/download/Thai-Hom-Mali_Rice-60.pdf

Tein, M., Timothy, D., Christine, H. (1998). Characterization of vacuum microwave, air and freeze dried carrot slices. Food Research International, 2, 111-117. http://dx.doi.org/10.1016/s0963-9969(98)00070-2

USDA. 2017, Grain: World markets and trade. Foreign Agricultural Service. (2017). Retrieved Feburary 10, 2018, from http://usda.mannlib.cornell.edu/MannUsda/viewDocumentInfo.do?documentID= 1487

Wang, J.P., An, H.Z., Jin, Z.Y., Xie, Z.J., Zhuang, H.N., Kim, J.M. (2013) Emulsifiers and thickeners on extrusion-cooked instant rice product. Journal of Food Science and Technology, 50, 655-666. https://doi.org/10.1007/s13197-0110400-6

Zhao, S., Xiong, S., Qiu, C., Xu, Y. (2007). Effect of microwaves on rice quality. Journal of Stored Products Research, 43, 496-502. https://doi.org/10.1016/j.jspr.2007.02.002 